Fall 10-1-2015

\title{
Platelet derived growth factor inhibitors: A potential therapeutic approach for ocular neovascularization.
}

\author{
Mohammad Ali Sadiq \\ University of Nebraska Medical Center \\ Mostafa Hanout \\ University of Nebraska Medical Center \\ Salman Sarwar \\ University of Nebraska Medical Center \\ Muhammad Hassan \\ University of Nebraska Medical Center \\ Diana V. Do \\ University of Nebraska Medical Center, diana.do@unmc.edu \\ See next page for additional authors \\ Tell us how you used this information in this short survey. \\ Follow this and additional works at: https://digitalcommons.unmc.edu/com_eye_articles \\ Part of the Ophthalmology Commons
}

\section{Recommended Citation}

Sadiq, Mohammad Ali; Hanout, Mostafa; Sarwar, Salman; Hassan, Muhammad; Do, Diana V.; Dong Nguyen, Quan; and Sepah, Yasir Jamal, "Platelet derived growth factor inhibitors: A potential therapeutic approach for ocular neovascularization." (2015). Journal Articles: Ophthalmology. 40.

https://digitalcommons.unmc.edu/com_eye_articles/40 


\section{Authors}

Mohammad Ali Sadiq, Mostafa Hanout, Salman Sarwar, Muhammad Hassan, Diana V. Do, Quan Dong Nguyen, and Yasir Jamal Sepah 
Review Article

\title{
Platelet derived growth factor inhibitors: A potential therapeutic approach for ocular neovascularization
}

Mohammad Ali Sadiq; Mostafa Hanout; Salman Sarwar; Muhammad Hassan; Diana V. Do; Quan Dong Nguyen; Yasir Jamal Sepah*

\begin{abstract}
Retinochoroidal vascular diseases are the leading causes of blindness in the developed world. They include diabetic retinopathy $(D R)$, retinal vein occlusion, retinopathy of prematurity, age-related macular degeneration (AMD), and pathological myopia, among many others. Several different therapies are currently under consideration for the aforementioned disorders. In the following section, agents targeting platelet-derived growth factor (PDGF) are discussed as a potential therapeutic option for retinochoroidal vascular diseases. PDGF plays an important role in the angiogenesis cascade that is activated in retinochoroidal vascular diseases. The mechanism of action, side effects, efficacy, and the potential synergistic role of these agents in combination with other treatment options is discussed. The future of treatment of retinochoroidal vascular diseases, particularly AMD, has become more exciting due to agents such as PDGF antagonists.
\end{abstract}

Keywords: Platelet derived growth factor, Retinal vascular disease, Age related macular degeneration, Diabetic retinopathy, PDGF

(C) 2015 The Authors. Production and hosting by Elsevier B.V. on behalf of Saudi Ophthalmological Society, King Saud University. This is an open access article under the CC BY-NC-ND license (http://creativecommons.org/licenses/by-nc-nd/4.0/).

http://dx.doi.org/10.1016/j.sjopt.2015.05.005

\section{Introduction}

Platelet-derived growth factor (PDGF) was first isolated from platelet extracts in the early 1970 s and classified as a mitogen for fibroblasts and cells of mesenchymal origin. ${ }^{1}$ The $\alpha$ granules of platelets are known to be a major storage site for PDGF; however, recent studies have also shown presence of PDGF in several other cell types. Mice studies have highlighted the essential role of PDGF in the early development of the embryo, with a deficiency resulting in defective formation of the lungs, vessels, placenta, brain, and skeleton. In these organs, cell types such as mesangial cells, pericytes, fibroblasts, and glial cells were shown to be dependent on PDGF. ${ }^{2}$
The PDGF family consists of four ligands: A, B, C and D. They function as homodimers with the exception of ligand " $A B^{\prime \prime}$, which acts as a heterodimer. ${ }^{3}$ All four PDGF ligands bind two structurally related tyrosine kinase cell surface receptors, $\alpha$ and $\beta,{ }^{4}$ which relay the message internally and initiate signal induction via Ras and phosphatidylinositol-II pathways. These pathways are essential for PDGF-induced cell migration and mitogenesis, respectively. ${ }^{5}$ PDGF-AA, $A B,-B B$ and $-C C$ activate the PDGF receptor- $\alpha$ (PDGFR $\alpha$ ) while PDGF-BB and -DD bind to PDGFR $\beta$ (Fig. 1). PDGF-A is expressed by neurons and astrocytes ${ }^{6}$ and, together with PDGFR $\alpha$, is responsible for recruitment and subsequent development of astrocyte precursors in the retina. ${ }^{6,7}$ PDGF-C plays a critical role in neuronal survival and prevention from

Received 23 June 2014; received in revised form 15 April 2015; accepted 9 May 2015; available online 6 June 2015

Stanley M. Truhlsen Eye Institute, University of Nebraska Medical Center, Omaha, NE, USA

* Corresponding author at: Stanley M. Truhlsen Eye Institute, University of Nebraska Medical Center, Omaha, NE $68198-5540$, USA. Tel.: +1 402 559 3262 .

e-mail address: yasir.sepah@unmc.edu (Y.J. Sepah).

Peer review under responsibility
of Saudi Ophthalmological Society, الجمعية النعودية لطب العبان King Saud University 


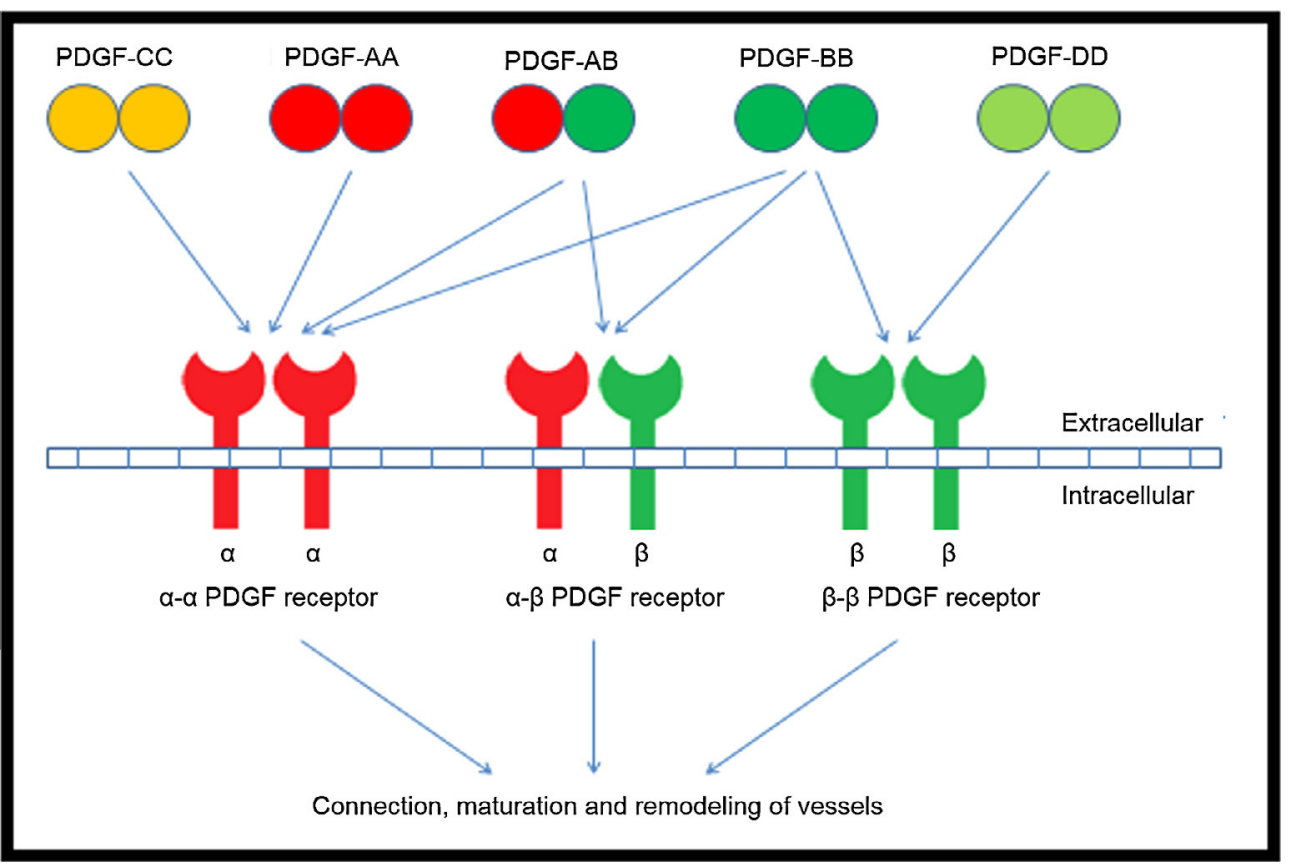

Figure 1. Flowchart demonstrating the PDGF ligand-receptor interaction.

apoptosis via regulation of expression of the glycogen synthase kinase $3 \beta .^{8}$ In animal models, eyes treated with PDGF showed decreased retinal pigment epithelial and photoreceptor degeneration.' Pericytes express PDGFR $\beta$, allowing PDGF-BB and PDGFR $\beta$ to play an important role in the maintenance of retinal vasculature. $^{10,11}$

PDGF over-activity has also been linked with several systemic conditions including autocrine stimulation of various cells in tumors, atherosclerosis, and fibrotic conditions such as lung, liver, and kidney fibrosis. ${ }^{12}$ In fact, PDGF antagonists are currently being evaluated for the treatment of pulmonary hypertension ${ }^{13}$ and several different tumors. ${ }^{14-16}$

\section{Methodology}

A systematic search of literature was conducted on PubMed, Scopus, and Google Scholar with no limitation on language or year of publication. Words searched included PDGF, Platelet Derived Growth Factor, PDGF AND antagonist, PDGF AND retinal diseases, PDGF AND AMD, PDGF AND DME, PDGF AND retinal vascular diseases.

\section{PDGF and retinochoroidal vascular diseases}

A common feature of most retinochoroidal diseases is some degree of vascular insult that leads to ischemia. Such injury consequently leads to release of a wide range of factors that alter the course of the disease process. It was first postulated in 1948 that an angiogenic factor was responsible for retinal neovascularization (NV). ${ }^{17}$ Since then, several other key factors have been identified for their critical role in the disease process. Hypoxia inducible factor-1 (HIF-1) was identified as a transcription factor that mediates increased expression of several genes associated with NV. These genes lead to the increased transcription of several key factors that are eventually responsible for new vessel formation; these include vascular endothelial growth factor (VEGF), PDGF, stromal derived growth factor-1 (SDF-1), and placental growth factor (PIGF).

Angiogenesis is considered to consist of five basic steps (Fig. 2) that include degradation of basement membranes, migration of endothelial cells, tube formation by endothelial cells, new basement membrane formation and finally, encirclement by pericytes for stabilization. In-vitro studies have demonstrated the role of PDGF in the angiogenesis process. ${ }^{18}$ It has been shown to promote migration and proliferation of endothelial cells along with an increase in the recruitment of pericytes. These findings, therefore, suggest that PDGF plays a key role in the angiogenesis cascade.

High glucose levels have been shown in-vitro to lead to increased expression of PDGF- $\beta$, and therefore, an increase in its binding to PDGF-BB. ${ }^{19}$ This glucose-related increased

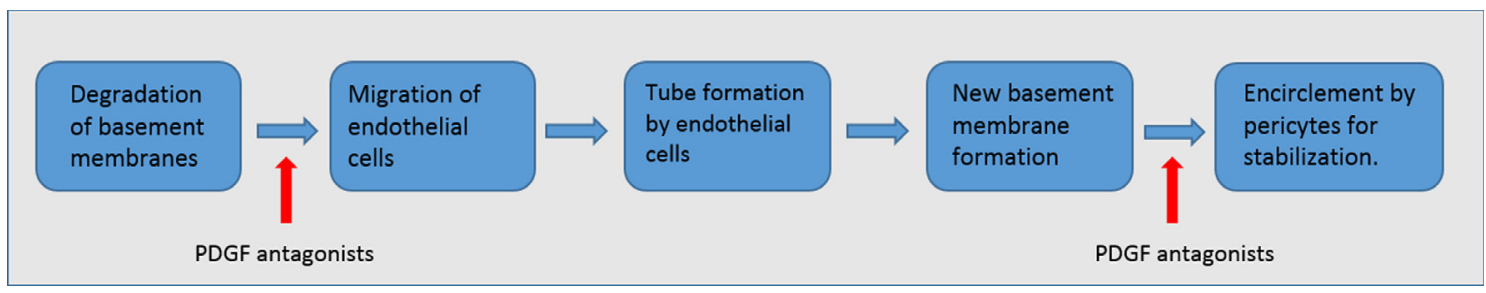

Figure 2. Flowchart depicting the various steps involved in the pathway of angiogenesis. 
expression was seen in mesangial cells, endothelial cells, and macrophages. Mice studies have shown that retina-specific expression of PDGF-B leads to severe NV and retinal detachment. ${ }^{20}$ Similar migratory and proliferative effects of PDGF have also been documented in rabbits. ${ }^{21} \mathrm{~A}$ study conducted by Freyberger et al. reported that PDGF levels were raised in both diabetic and non-diabetic proliferative retinopathy. ${ }^{22}$ According to Robbins et al, PDGF-A staining was limited to vessels in the normal retina and choroid, whereas in the diseased retina and choroid, the staining was widespread in the cytoplasm of cells such as macrophages, RPE cells, and fibroblast-like cells. Similarly, unlike normal RPE cells, RPE cells within NV membranes stained strongly positive for PDGF-B receptors, suggesting increased concentrations of both ligands and receptors in such conditions. ${ }^{23}$ Therefore, it might be postulated that PDGF, together with other growth factors, plays an integral part in the NV process found in diabetic eyes.

One possible explanation for the involvement of PDGF in the NV process includes entry of platelets and monocytes into the vitreous and subretinal space upon injury to the blood-retina barrier, with subsequent platelet aggregation and PDGF discharge. Interleukins such as IL-1 and TGF-B, released from activated macrophages may lead to further synthesis of PDGF.

\section{Studies evaluating the role of anti-PDGF agents in retinochoroidal vascular diseases}

Several treatment strategies for retinochoroidal vascular diseases have been aimed at blocking the effects of PDGF in the angiogenesis process.

In a mice study, Dong et al. tested the effect of a designed ankyrin repeat protein (DARPin) that selectively binds to and antagonizes PDGF-BB in subretinal NV; the effect was compared to a similar protein that antagonized VEGF-A. According to the study, intra-peritoneal injection of $10 \mathrm{mg} / \mathrm{kg}$ of the anti-PDGF protein or $1 \mathrm{mg} / \mathrm{kg}$ of the anti-VEGF protein significantly suppressed subretinal NV. ${ }^{24}$ The effect of injection of $1 \mathrm{mg} / \mathrm{kg}$ anti PDGF-DARPin was not significant; however, when combined with $1 \mathrm{mg} / \mathrm{kg}$ anti-VEGF-A DARPin, the suppression was greater than that achieved by the anti-VEGF-DARPin alone. Similarly, strong suppression of retinal NV was also achieved with $1.85 \mu \mathrm{g}$ of anti-PDGF-BB DARPin. These findings suggest that PDGF is a valid target for the treatment of ocular NV.

Several clinical trials evaluating the role of PDGF antagonists in human eyes are currently ongoing (Table 1). These studies are looking at the safety profile of the available PDGF antagonists as well as their efficacy in comparison with and in combination with other currently available VEGF antagonists.

Ophthotech (New York, U.S.A.) developed a high affinity PDGF antagonist called E10030. This molecule binds to PDGF and blocks its binding to PDGFR- $\beta$. In-vitro/in-vivo studies using this compound have shown the effectiveness of its combination with an anti-VEGF agent in preventing the formation of CNV, as well as in the stripping of pericytes from vessels that have already formed, leading to their regression. A phase-I clinical trial that investigates the safety and tolerability of E10030 in humans in combination with ranibizumab or as a monotherapy has been completed. ${ }^{25} \mathrm{~A}$

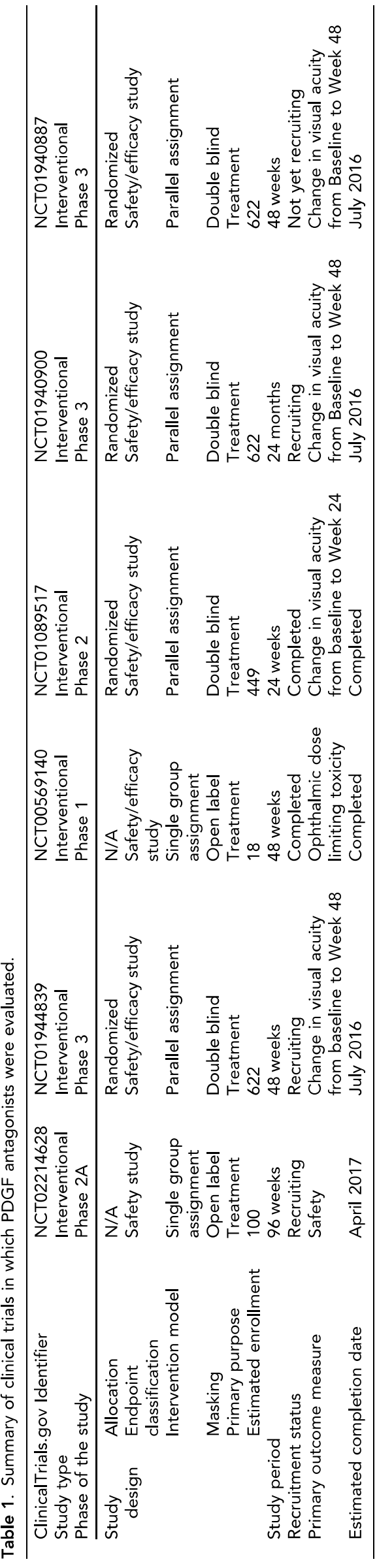


dose-escalation (0.03 $\mathrm{mg}, 0.3 \mathrm{mg}, 1.5 \mathrm{mg}$ and $3.0 \mathrm{mg}$ ) scheme was used. All dose levels were well tolerated with no dose-related toxicities being reported. A significant visual gain (increase in BCVA of $\geqslant 15$ letters) was seen in $59 \%$ of patients at week 12. Central retinal thickness (CRT), detected by optical coherence tomography (OCT) showed a decrease in thickness at all study visits for all treatment groups. The mean CRT was $395 \mu \mathrm{m}$ at baseline, $251 \mu \mathrm{m}$ at week 4, $231 \mu \mathrm{m}$ at week 8 , and $229 \mu \mathrm{m}$ at week 12. Fluorescein angiography (FA) also demonstrated neovascular regression in all patients from baseline to week 12, with the mean decrease in CNV size being 85.5\% compared to baseline.

In conclusion, E10030 showed potential as a possible future therapeutic agent when used in combination with ranibizumab. ${ }^{26}$ Following the results of the phase-I study, a phase-II, randomized, double-blind clinical trial was initiated to further evaluate E10030. ${ }^{27}$ The study enrolled 449 patients who were randomized in a 1:1:1 ratio into the following groups: $0.3 \mathrm{mg}$ anti-PDGF with $0.5 \mathrm{mg}$ ranibizumab, $1.5 \mathrm{mg}$ anti-PDGF with $0.5 \mathrm{mg}$ ranibizumab, and a sham injection given in conjunction with ranibizumab $0.5 \mathrm{mg}$. The primary outcome measure of the study was change in BCVA from baseline to week 24 . The study results reported that combination therapy of anti-PDGF and ranibizumab was superior to ranibizumab alone, with the combination arm showing $62 \%$ improvement in vision. Mean improvement in BCVA was: 10.6 letters, 8.74 letters and 6.52 letters in the $1.5 \mathrm{mg}$ combination group, $0.3 \mathrm{mg}$ combination group and the ranibizumab monotherapy group respectively $(P=0.019$ for ranibizumab only in comparison with each combination group). The BCVA outcomes in the combination groups were also superior to the monotherapy group when the patients were separately assessed after being subdivided into two groups based on their baseline CRT (CRT $<316 \mu \mathrm{m}$ or CRT $>480 \mu \mathrm{m}){ }^{28}$

A phase-III, randomized, double-blind clinical trial has recently been initiated for E10030. ${ }^{29}$ The study aims to enroll 622 patients. It will compare the effect of $1.5 \mathrm{mg}$ E10030 intravitreal injection $+0.5 \mathrm{mg}$ ranibizumab intravitreal injection to E10030 sham intravitreal injection + ranibizumab $0.5 \mathrm{mg}$ intravitreal injection. The primary outcome measure of the study is the mean change in BCVA from baseline to month 12. Another similar phase-III study has been initiated that plans to compare the combination therapy of E10030 with that of aflibercept or bevacizumab. This study is currently not recruiting. ${ }^{30}$ Table 1 provides a summary of these trials.

\section{Summary and conclusion}

Anti-VEGF monotherapy, has no doubt, proven to be effective in the treatment of AMD. However, the outcomes of patients receiving anti-VEGF therapy has fallen short of expectations for two-thirds of the patients in most clinical trials. Similarly, the long term effects of anti-VEGF therapy have also come under scrutiny in recent times. According to the SEVEN-UP study (Seven-year outcomes in ranibizumabtreated patients in ANCHOR, MARINA, and HORIZON: a multicenter cohort), at a mean of 7.3 years after entering the ANCHOR or MARINA trial, BCVA in $34 \%$ of study eyes declined by 15 letters or more, with an overall mean decline of 8.6 letters $(P<0.005)$. Similar limitations in the long term outcomes of patients were also seen in the comparison of AMD treatment trials (CATT) study. ${ }^{31}$

By blocking pericyte's recruitment, survival and maturation, PDGF antagonists inhibit the development and maturation of newly formed vessels, thereby, offering an exciting new treatment option for patients with neovascular AMD.

Recent trials comparing the benefit of combination therapy of ranibizumab and PDGF antagonists to ranibizumab monotherapy have shown superiority of the combination therapy. This might be explained by the fact that both VEGF and PDGF levels increase in neovascularization, and the VEGF is neutralized by anti-VEGF but PDGF continues to work in the absence of PDGF antagonists. In fact, chronic anti-VEGF treatment causes PDGF upregulation, leading to pericyte recruitment and neovascular membrane stabilization. $^{32}$ By using PDGF antagonists in combination with VEGF, this vessel protective mechanism may be surpassed to provide a therapeutic option, which treats neovascularization in a more effective manner.

Although PDGF antagonists might have a potential role for treatment in AMD, their role in the treatment of DR might be limited due to the fact that PDGF is required for pericyte retention and recruitment. ${ }^{33}$

\section{Conflict of interest}

Dr. Nguyen and Dr. Do serve on the Scientific Advisory Boards for Genentech, Inc. and Regeneron, Inc. Dr. Nguyen serves on the Scientific Advisory Board for Bausch and Lomb, Inc.

\section{References}

1. Demoulin JB, Montano-Almendras CP. Platelet-derived growth factors and their receptors in normal and malignant hematopoiesis. Am J Blood Res 2012;2(1):44-56 PubMed PMID: 22432087. Pubmed Central PMCID: PMC3301440. Epub 2012/03/21. Eng.

2. Andrae J, Gallini R, Betsholtz C. Role of platelet-derived growth factors in physiology and medicine. Genes Dev 2008;22(10):1276312 PubMed PMID: 18483217. Pubmed Central PMCID: PMC2732412. Epub 2008/05/17. Eng.

3. Edqvist PH, Niklasson M, Vidal-Sanz M, Hallbook F, Forsberg-Nilsson K. Platelet-derived growth factor over-expression in retinal progenitors results in abnormal retinal vessel formation. PloS One 2012;7(8):e42488 PubMed PMID: 22880002. Pubmed Central PMCID: PMC3411765. Epub 2012/08/11. Eng.

4. Heldin $\mathrm{CH}$, Westermark $\mathrm{B}$. Mechanism of action and in vivo role of platelet-derived growth factor. Physiol Rev 1999;79(4):1283-316 PubMed PMID: 10508235. Epub 1999/10/03. Eng.

5. Alvarez RH, Kantarjian HM, Cortes JE. Biology of platelet-derived growth factor and its involvement in disease. Mayo Clin Proc 2006;81(9):1241-57 PubMed PMID: 16970222. Epub 2006/09/15. Eng.

6. Fruttiger M, Calver AR, Richardson WD. Platelet-derived growth factor is constitutively secreted from neuronal cell bodies but not from axons. Curr Biol : CB 2000;10(20):1283-6 PubMed PMID: 11069109. Epub 2000/11/09. Eng.

7. Reneker LW, Overbeek PA. Lens-specific expression of PDGF-A in transgenic mice results in retinal astrocytic hamartomas. Invest Ophth Vis Sci 1996;37(12):2455-66 PubMed PMID: 8933762. Epub 1996/11/ 01. Eng.

8. Tang Z, Arjunan P, Lee C, Li Y, Kumar A, Hou X, et al. Survival effect of PDGF-CC rescues neurons from apoptosis in both brain and retina by regulating GSK3beta phosphorylation. J Exp Med 2010;207(4):86780 PubMed PMID: 20231377. Pubmed Central PMCID: 2856029.

9. Wang Y, Abu-Asab MS, Yu CR, Tang Z, Shen D, Tuo J, et al. Plateletderived growth factor (PDGF)-C inhibits neuroretinal apoptosis in a murine model of focal retinal degeneration. Lab Invest; A J Tech Method Pathol 2014;94(6):674-82 PubMed PMID: 24709779. Pubmed Central PMCID: 4039574. 
10. Lindahl $P$, Johansson $B R$, Leveen $P$, Betsholtz $C$. Pericyte loss and microaneurysm formation in PDGF-B-deficient mice. Science (New York, NY) 1997;277(5323):242-5 PubMed PMID: 9211853. Epub 1997/07/11. Eng.

11. Mudhar HS, Pollock RA, Wang C, Stiles CD, Richardson WD. PDGF and its receptors in the developing rodent retina and optic nerve. Development (Cambridge, England) 1993;118(2):539-52 PubMed PMID: 8223278. Epub 1993/06/01. Eng.

12. Trojanowska M. Role of PDGF in fibrotic diseases and systemic sclerosis. Rheumatology (Oxford, England) 2008;47 Suppl 5:v2-4 PubMed PMID: 18784131. Epub 2008/09/17. Eng

13. Grimminger F, Schermuly RT. PDGF receptor and its antagonists: role in treatment of PAH. Adv Exp Med Biol 2010;661:435-46 PubMed PMID: 20204747. Epub 2010/03/06. Eng.

14. Hosaka K, Yang Y, Seki T, Nakamura M, Andersson P, Rouhi P, et al. Tumour PDGF-BB expression levels determine dual effects of anti-PDGF drugs on vascular remodelling and metastasis. Nature Commun 2013;4:2129.

15. Polverino A, Coxon A, Starnes C, Diaz Z, DeMelfi T, Wang L, et al. AMG 706, an oral, multikinase inhibitor that selectively targets vascular endothelial growth factor, platelet-derived growth factor, and kit receptors, potently inhibits angiogenesis and induces regression in tumor xenografts. Can Res 2006;66(17):8715-21.

16. Crino L, Metro G. Therapeutic options targeting angiogenesis in nonsmall cell lung cancer. Eur Respir Rev: An Off J Eur Respir Soc 2014;23(131):79-91 PubMed PMID: 24591665. Epub 2014/03/05. Eng.

17. Michaelson I. The mode of development of the vascular system of the retina with some observations on its significance for certain retinal diseases. Trans Ophthalmol Soc UK 1948;68:137-80.

18. Sato N, Beitz JG, Kato J, Yamamoto M, Clark JW, Calabresi P, et al Platelet-derived growth factor indirectly stimulates angiogenesis in vitro. Am J Pathol 1993;142(4):1119-30.

19. Inaba T, Ishibashi S, Gotoda T, Kawamura M, Morino N, Nojima $Y$, et al. Enhanced expression of platelet-derived growth factor-beta receptor by high glucose involvement of platelet-derived growth factor in diabetic angiopathy. Diabetes 1996;45(4):507-12. PubMed PMID: 8603774. Epub 1996/04/01. Eng.

20. Seo MS, Okamoto N, Vinores MA, Vinores SA, Hackett SF, Yamada $\mathrm{H}$, et al. Photoreceptor-specific expression of platelet-derived growth factor-B results in traction retinal detachment. Am J Pathol 2000;157(3):995-1005 PubMed PMID: 10980138. Pubmed Central PMCID: PMC1885694. Epub 2000/09/12. Eng

21. Koyama N, Watanabe S, Tezuka M, Morisaki N, Saito Y, Yoshida S. Migratory and proliferative effect of platelet-derived growth factor in rabbit retinal endothelial cells: evidence of an autocrine pathway of platelet-derived growth factor. J Cell Physiol 1994;158(1):1-6 PubMed PMID: 7505273. Epub 1994/01/01. Eng.

22. Freyberger $H$, Brocker $M$, Yakut $H$, Hammer $J$, Effert $R$, Schifferdecker $E$, et al. Increased levels of platelet-derived growth factor in vitreous fluid of patients with proliferative diabetic retinopathy. Exp Clin Endocrinol Diabet: Off J, German Soc Endocrinolo and German Diabetes Assoc 2000;108(2):106-9 [PubMed PMID: 10826517. Epub 2000/05/29. Eng].

23. Robbins SG, Mixon RN, Wilson DJ, Hart CE, Robertson JE, Westra I, et al. Platelet-derived growth factor ligands and receptors immunolocalized in proliferative retinal diseases. Invest Ophthalmol Visual Sci 1994;35(10):3649-63 PubMed PMID: 8088954. Epub 1994/ 09/01. Eng.

24. Dong A, Seidel C, Snell D, Ekawardhani S, Ahlskog JK, Baumann M, et al. Antagonism of PDGF-BB suppresses subretinal neovascularization and enhances the effects of blocking VEGF-A. Angiogenesis 2013 PubMed PMID: 24154861. Epub 2013/10/25. Eng].

25. Ophthotech C. A Phase 1, Safety, Tolerability and Pharmacokinetic Profile of Intravitreous Injections of E10030 (Anti-PDGF Pegylated Aptamer) in Subjects With Neovascular Age-Related Macular Degeneration. US National Institutes of Health. 20072013 December 12 <http://clinicaltrials.gov/show/NCT00569140>.

26. Jordi Mones M, Barcelona, Spain. Inhibiting VEGF and PDGF to Treat AMD REVIEW of Ophthalmology2011 http://www. revophth.com/content/d/retinal_insider/c/29979/.

27. Ophthotech C. A Safety and Efficacy Study of E10030 (Anti-PDGF Pegylated Aptamer) Plus Lucentis for Neovascular Age-Related Macular Degeneration. US National Institutes of Health. 2010 2013 December $12 \quad<$ http://clinicaltrials.gov/ct2/show/ NCT01089517?term $=$ NCT\&rank $=1>$.

28. Dugel, PU. Anti-PDGF combination therapy in neovascular agerelated macular degeneration: results of a phase $2 b$ study. RETINA TODAY. March, 2013 <http://retinatoday.com/2013/03/anti-pdgfcombination-therapy-in-neovascular-age-related-maculardegeneration-results-of-a-phase-2b-study/>

29. A Phase 3 Safety and Efficacy Study of Fovista ${ }^{\mathrm{TM}}$ (E10030) Intravitreous Administration in Combination With Lucentis ${ }^{\circledR}$ Compared to Lucentis ${ }^{\circledR}$ Monotherapy 2013 <http://clinicaltrials. gov/ct2/show/record/NCT01940900?term =NCT01940900\&rank=1>.

30. A Phase 3 Safety and Efficacy Study of FovistaTM (E10030) Intravitreous Administration in Combination With Either Avastin ${ }^{\circledR}$ or Eylea ${ }^{\circledR}$ Compared to Avastin ${ }^{\circledR}$ or Eylea ${ }^{\circledR}$ Monotherapy; 2013.

31. Martin DF, Maguire MG, Fine SL, Ying GS, Jaffe GJ, Grunwald JE, et al. Ranibizumab and bevacizumab for treatment of neovascular age-related macular degeneration: two-year results. Ophthalmology 2012;119(7):1388-98 PubMed PMID: 22555112. Pubmed Central PMCID: PMC3389193. Epub 2012/05/05. eng.

32. Dugel PU. Anti-PDGF combination therapy in neovascular agerelated macular degeneration: results of a phase $2 b$ study 2013 ; (March).

33. Betsholtz $C$. Insight into the physiological functions of PDGF through genetic studies in mice. Cytok Growth Factor Rev 2004;15(4):215-28 PubMed PMID: 15207813. Epub 2004/06/23. Eng. 